\title{
Svante August Arrhenius
}

\section{The Founder of the Theory of Electrolytic Dissociation}

\section{By Professor Wilhelm Ostwald} S VANTE AUGUST ARRHENIUS was born February
19th, 1859, near Upsala. His ancestors were farmers, and the name Arrhenius is a Latinized derivative meaning a river bank the name of the family estate in the $c$ bool svante exhibited remarkable precocity and dis tinguished himself particularly in mathematics, phy biology. He entered the University of Upsala in 1876, but in 1881 went to Prof. Edlund in $\mathrm{S} \mathrm{tock}$ holm the degree of physics in 1884 . His graduation thesis, "A Study of the Conductivity of Electrolytes," publishe in the same ma the same pression upon me. I have devoted part of my life to the study of the chemical relation between acids and bases, an when that paper appeared, I had obtained for the specific affinities of various acids values closely a greein with the reln with the result hich Arrhenius had reached by a very different road. The method by which Arrhenius had attacked and partly solved the problem was fa more comprehensiv and fertile own. I was then connected with the polytechnical schoo of Riga, Russia, and there I repeated and extended the exper ments by which Arrhenius had proved the approximate proportionality of the chemical affinities of acids and bases to th i $r$ electroly tic th e lr electrolytical es, a n d published the results. Then I went to Upsala to support Arrhenius, whose views were regarded as he terodox in obtain terodox, in obtain in the university. A year later we worked together for severa months at Riga.

In 1887 Arrhenius published his theory of electrolytic dissociation, probably the

most important and prolific of his many achievements, which explained the observed anomalies in the freeing point of electrolytes and interpreted as a dissociation factor the irrational coefficient $(\sqrt{-1})$ in Van't Hoff's then new and much discussed theory of osmotic pressure. The new theory of electrolysis rapidly developed, explaining many well known but little understood phenomena of chemical equilibrium, analytica reactions, the concentration of electrolytes, the galvanic battery, the solubility of gases, etc.

This rapid success spared Arrhenius the waste of energy in polemics which the iconoclast usually suffers, and also assured him means of support and of further scientific activity. In 1891 he was called to the University of Giessen, but he preferred to accept

a position in the new University of Stockholm, where his subsequent promotion to a professorship was due mainly to the influence of foreign scientists. In 1897, however, his colleagues chose him as their rector or president and he was twice re-elected to this position, which he finally declined in the interest of Nobel Physical Institute.
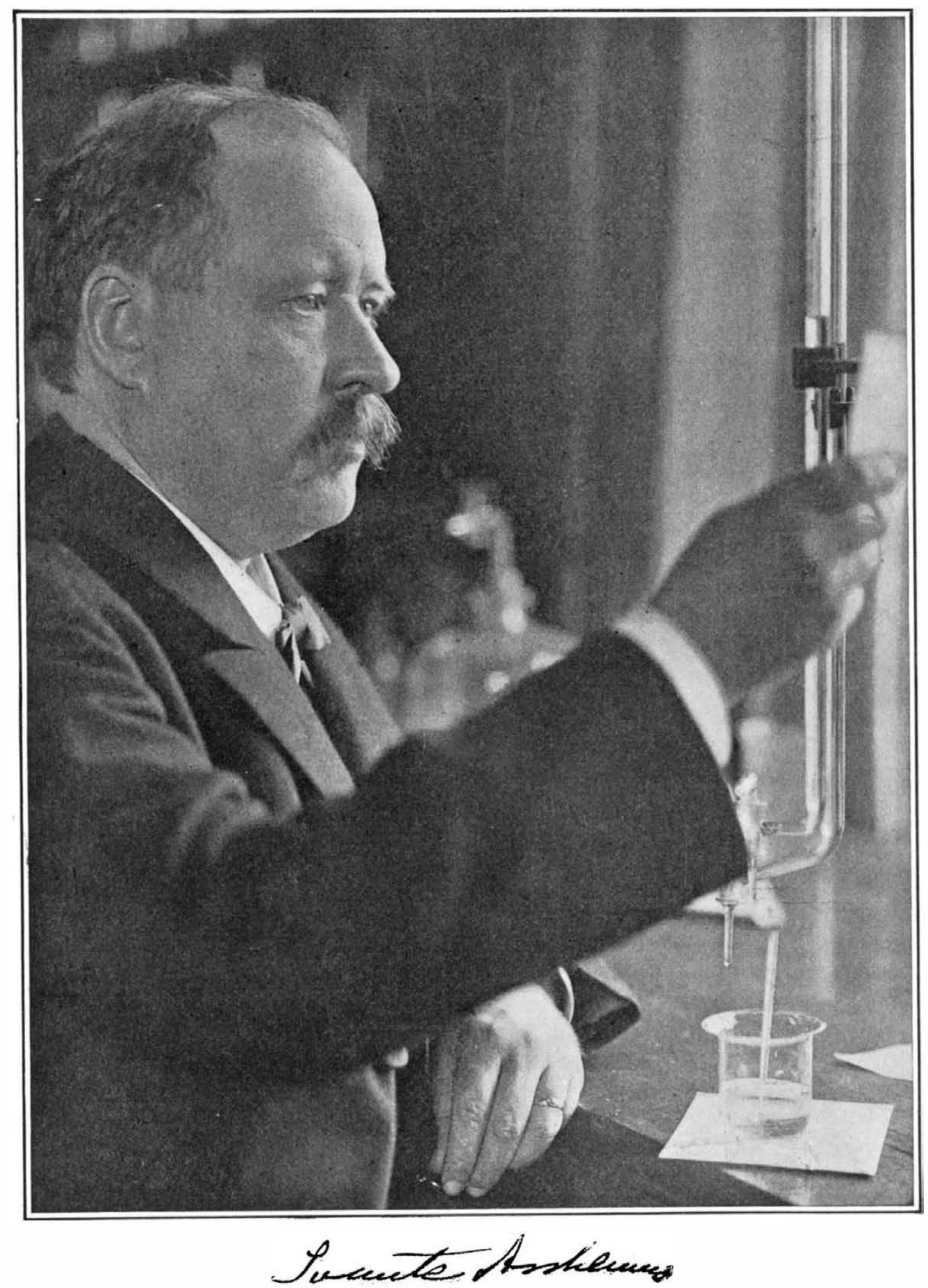

his scientific work. In 1905 he became director of the

The theory of electrolytic dissociation soon gained so many enthusiastic young advocates that it con tinued to develop without direct aid from the founder except where such aid was required to refute criticism and enlighten skeptics. In 1890 Arrhenius, Van't Hoff and I were invited to discuss the theory of solution with a committee of the British Association, the members of which were at least partially converted to the new views by their foreign guests, aided by William Ramsay. The new theory made rapid progress against strong opposition in Great Britain. French chemists refused to discuss or consider the theory at that time and they are still far behind their
German and British colleagues in this line of research. Arrhenius published a great many papers in the ten years that followed the announcement of the dissociation theory. In the succeeding decade his duties as rector of the new university, to which he devoted himself with great diligence and success, diminished his scientific output, but two new and very important. phases of his activity belong to this period.

In connection with his early studies of the conductivity of solutions he had investigated electric conduction in silver chloride in light and in darkness, in phosphorescent and illuminated air, and in B u ns en flames in which various salts were vaporized. In 1888 he studied t? influence of $\mathrm{the}$ sun's rays on the electrical state of the atmosphere. In $1895-8$, in collaboration with Ekholm, he published re searches on the moon's influence on a u ro ras, thunderstorms and terrestrial electricity, the 26 day period of thunderstorms and auroras, and the effect produced on the earth's temperature by the carbon dioxide of the atmosphere. In 1898, also, a p peared his remarkable paper on the effect of cosmical influences upon physiological conditions, which has a? parently been overlooked by recent students of periodic vital phenomena.

In 1905 he aston ished the scientific world with his two volume Text Book of Cosmical Physics, c o n tain ing many bold and original ideas in regard to the constitution and origin of the heaven ly bodies. Still more recently appeared "Worlds in the Making," which exhibits in a striking manner the author's characteristic traits, startling boldness of conception, the ability to regard apparently disconnected facts from a common viewpoint,
and a masterly simplicity and comprehensiveness of

The most striking novelty in the cosmogony of $\mathrm{Ar}$ rhenius is the introduction of the pressure of radiation, which appears to be a very active factor, not only in the formation of comets' tails, but also in many more important cosmical processes.

Arrhenius has recently taken up the study of serum-therapy and has, explained Ehrlich's important discoveries by a theory of unsaturated compounds, analogous to that which exists between weak acids and bases.-Adapted from an article published in "Die Forderung des Tages," Leipzig, 1910. Akademische Verlagsgesellschaft, m. b. H. 